\title{
Response to First-line Recurrence Treatment Influences Survival in Hormone Receptor-positive, HER2-negative Breast Cancer: A Multicenter Study
}

\author{
JUN YAMAMURA ${ }^{1,2}$, SHUNJI KAMIGAKI ${ }^{1}$, MASAKI TSUJIE ${ }^{1}$, JUNYA FUJITA $^{1}$, \\ HIROKI OSATO $^{1}$, CHIHIRO HIGASHI $^{2}$, HIROFUMI KANAIZUMI ${ }^{2}$, YUMIKO TANAKA ${ }^{2}$, \\ MIKA HAMADA ${ }^{2}$, WATARU SHINZAKI ${ }^{2}$, YUKIHIKO HASHIMOTO ${ }^{2}$ and YOSHIFUMI KOMOIKE ${ }^{2}$ \\ ${ }^{1}$ Department of Surgery, Sakai City Medical Center, Osaka, Japan; \\ ${ }^{2}$ Division of Breast and Endocrine Surgery, Department of Surgery, \\ Kindai University Faculty of Medicine, Osaka, Japan
}

\begin{abstract}
Background/Aim: Little evidence is currently available on significant determinants of post-recurrence survival for patients with hormone receptor-positive $(H R+)$, HER2-negative (HER2-) breast cancer. The objective of this study was to evaluate factors influencing post-recurrence survival in HR+/HER2-breast cancer. Patients and Methods: A cohort of 236 patients with recurrent HR+/HER2- breast cancer was retrospectively analyzed to identify significant factors correlating with prognosis after recurrence. Results: Multivariate analysis revealed independent prognostic factors of poor survival as follows: short intervals between recurrence and the end of adjuvant endocrine therapy (ET; $p=0.046)$; short disease-free intervals $(p=0.019)$; liver metastasis $(p=0.007)$ or multiple metastases $(p<0.001)$ at recurrence; and a poor response to first-line treatment $(p<0.001)$. A poor first-line treatment response was significantly associated with a shorter response to a subsequent treatment line $(p=0.007)$. Logistic regression analysis indicated that liver metastasis significantly increased the risk of a poor first-line-ET response ( $p=0.009$ ). Conclusion: The first-line treatment response was the key to post-recurrence survival in patients with $H R+/ H E R 2$ - breast cancer. Particularly poor responses led to subsequent unfavorable prognostic outcomes.
\end{abstract}

This article is freely accessible online.

Correspondence to: Jun Yamamura, Department of Surgery, Sakai City Medical Center, 1-1-1, Ebaraji-cho, Nishi-ku, Sakai City, Osaka 593-8304, Japan. Tel: +81 722721199, Fax: +81 722729911, email: june10th68@gmail.com

Key Words: Breast cancer, recurrence, survival, hormone receptorpositive, HER2-negative.
Breast cancer is the most common cancer diagnosed in women, and leads to cancer-related mortality throughout the world $(1,2)$. The majority of patients with breast cancer are diagnosed at an early disease stage, receive standard care, and become long-term disease-free survivors (3-5). However, 20$30 \%$ of patients experience distant metastasis, despite progress with an adjuvant treatment (3-6). Patients with hormone receptor-positive $(\mathrm{HR}+)$, human epidermal growth factor receptor 2-negative (HER2-) breast cancer that develop recurrent disease during or after adjuvant endocrine therapy (ET) are generally incurable; in which cases the main treatment goal is symptom palliation $(7,8)$. When recurrent disease is not life-threatening, ET is the most preferred firstline treatment (9). Prognostic factors related to survival after a first recurrence of HR+/HER2- breast cancer have been studied before, but a very wide variety of clinical factors were associated with better or worse outcomes (10-12). The management of recurrent breast cancer has increasingly improved $(13,14)$, but little evidence is available for determining the optimal first-line treatment strategy for patients with recurrent metastatic HR+/HER2- breast cancer. These patients may have developed resistance to metastatic cancer treatments due to continuous adjuvant therapy $(15,16)$. Therefore, identification of important clinical clues for a favorable prognosis could improve the long-term quality of life in these patients. Moreover, it is critical to gain a deeper understanding of responses to treatments for recurrence to facilitate the design of appropriate treatment strategies and the use of novel targeted agents.

In the present retrospective study, we evaluated potential influencing factors to determine significant correlations with post-recurrence survival. Identifying prognostic factors after recurrence of $\mathrm{HR}+/ \mathrm{HER} 2$ - breast cancer might improve the delivery of healthcare to high-risk groups and play an important role in optimal patient treatment and care. 


\section{Patients and Methods}

Patient characteristics. The clinical records of 236 patients with recurrent metastatic HR+/HER2- breast cancer treated between January 2000 and December 2013 at Sakai City Medical Center and Kindai University Hospital, in Japan, were retrospectively reviewed. Recurrence was defined as a distant metastasis that occurred after the primary breast cancer was removed and standard adjuvant treatment was performed. Patients with locoregional recurrence were excluded from this analysis. This study was approved by the institutional review board of our hospitals and all enrolled patients provided informed consent.

Subtype classification. Positivity for the estrogen receptor (ER+) or progesterone receptor ( $\mathrm{PR}+$ ) was defined as a score $\geq 3$ using the Allread scoring system; hormone receptor-positivity (HR+) was defined as ER+ and/or PR+. HER2- negativity was defined as an immunohistochemistry score of $0,1+$, or $2+$ and as a negative fluorescence in situ hybridization result (ratio $<2.0$ ).

Survival outcomes. For patients diagnosed with a first distant recurrence, we assessed the clinicopathological features, treatment regimen, metastatic sites, progression time, and survival outcomes. Overall survival (OS) was defined as the time from the date of the first distant recurrence to the time of death or last follow-up. The treatment-free interval (TFI) was defined as the time between the end of adjuvant treatment and the first distant recurrence. The disease-free interval (DFI) was defined as the interval between the diagnosis of the primary non-metastatic breast cancer and the date of the first distant recurrence. A good response to first-line treatment was defined as a first-line treatment with duration $\geq 6$ months; a poor response was defined when duration was less than 6 months. Progression-free survival (PFS) during a second-line treatment was analyzed in groups with either a good or a poor response to firstline treatment.

Statistical analysis. OS and PFS plots were calculated with the Kaplan-Meier method. Survival curve distributions were compared with the log-rank test. A Cox proportional hazard regression was used to examine associations between different prognostic indicators (i.e., patient- and disease-related clinicopathological factors) and survival outcomes. Regressions were analyzed with hazards ratios (HRs) and 95\% confidence intervals (CIs). HRs $>1.0$ indicated an increased risk of death. Logistic regression was performed to identify risk factors for a poor response to first-line-chemotherapy (CT) and first-line-ET treatments, and those results were analyzed with odds ratios (OR) and 95\% CIs. All tests were two-tailed; $p$-values $<0.05$ were considered significant. Statistical analyses were performed with the Statistical Software package, SPSS (v.17.0; Chicago, IL, USA).

\section{Results}

Characteristics of patients and survival outcomes. Our analyses included 236 patients with recurrent metastatic HR+/HER2- breast cancer (Table I). A poor prognosis was significantly correlated to older age ( $\geq 70$ years at diagnosis), low ER expression, anthracycline or taxane alone as adjuvant CT, a short DFI ( $<2$ years) or TFI ( $<1$ year), liver metastasis or multiple metastases at first recurrence, and a poor response to first-line treatment. In contrast, a good prognosis was significantly correlated with a longer duration ( $\geq 5$ years) of adjuvant ET and bone-only metastasis at first recurrence. Survival plots showed that patients with a good response to first-line-CT or first-line-ET treatments had significantly better survival rates after recurrence, compared to those with poor responses to first-line-CT ( $p=0.028$; Figure 1A) or firstline-ET treatments $(p<0.001$; Figure 1B).

Multivariate analysis of factors related to survival after recurrence. The multivariate analysis included all prognostic factors that achieved significance in the univariate analysis (Table II). The multivariate analysis revealed four significantly independent prognostic factors related to an unfavorable survival rate after recurrence: i) a short TFI $(<1$ year; $p=0.046)$, ii) a liver metastasis $(p=0.007)$ or iii) multiple metastases at first recurrence $(p<0.001)$, and iv) a poor response to first-line treatment $(p<0.001)$.

PFS on second-line treatment for recurrence. Survival plots showed that the PFS was significantly shorter for patients with a poor response to first-line treatment, compared to those with a good response (median PFS: 4.63 months vs. 8.60 months, $p=0.001$; Figure 2).

Risk factors for a poor response to first-line treatment. A logistic regression analysis showed that a metastasis to bone only significantly increased the risk of a poor response to first-line-CT ( $p=0.014$; Table III). Moreover, liver metastasis was a significant risk factor for a poor response to first-lineET ( $p=0.009$; Table IV).

\section{Discussion}

Several concepts regarding prognosis in HR+/HER2- breast cancer patients were considered important in evaluating their survival after recurrence. First, we considered the primary biological parameters, including nodal status, histological grade, progression degree, and HR or HER2 status. Second, time-based variables that described the time before recurrence were considered, such as duration of adjuvant treatment, TFI, and DFI. Third, we considered postrecurrence characteristics; i.e., metastatic sites and the response or resistance to treatment.

Our cohort included about $70 \%$ patients with $\mathrm{TFI}<1$ year, which indicated that most registered patients experienced recurrences during or soon after adjuvant ET. These patients should be considered resistant to ET; therefore, they need a more aggressive treatment. Our multivariate analysis showed that $\mathrm{TFI}<1$ year was an independent prognostic factor for post-recurrence survival. Consistent with previous studies, we also found that DFI was a strong significant prognostic factor (17-19). It is reasonable to assume that, due to advances in 
Table I. Patient characteristics and median overall survival (OS).

\begin{tabular}{|c|c|c|c|c|}
\hline \multirow[t]{2}{*}{ Characteristics } & \multirow[t]{2}{*}{$\mathrm{N}(\%)$} & \multirow{2}{*}{$\begin{array}{l}\text { Median OS from } \\
\text { recurrence (years) }\end{array}$} & \multicolumn{2}{|c|}{ Univariate analysis } \\
\hline & & & $\operatorname{HR}(95 \% \mathrm{CI})$ & $p$-Value \\
\hline All & $236(100 \%)$ & 4.54 & & \\
\hline \multicolumn{5}{|l|}{ Age at diagnosis } \\
\hline$<50$ years & $80(34 \%)$ & 4.51 & $0.432(0.235-0.795)$ & 0.007 \\
\hline $50-70$ years & $124(52 \%)$ & 5.05 & $0.428(0.241-0.760)$ & 0.004 \\
\hline$\geq 70$ years & $32(14 \%)$ & 1.64 & 1.00 & \\
\hline \multicolumn{5}{|l|}{ Stage } \\
\hline I & $36(15 \%)$ & 6.30 & 1.00 & \\
\hline IIA+IIB & $74+68(60 \%)$ & 4.44 & $1.012(0.758-1.351)$ & 0.937 \\
\hline IIIA+IIIB+IIIC & $30+21+7(25 \%)$ & 4.73 & $1.099(0.780-1.546)$ & 0.590 \\
\hline \multicolumn{5}{|l|}{ Number of positive nodes } \\
\hline 0 & $75(32 \%)$ & 5.72 & $0.798(0.601-1.061)$ & 0.121 \\
\hline $1-3$ & $78(33 \%)$ & 4.42 & $0.837(0.634-1.106)$ & 0.211 \\
\hline $4-10$ & $51(22 \%)$ & 4.58 & $0.804(0.590-1.094)$ & 0.165 \\
\hline $11-$ & $32(14 \%)$ & 2.60 & 1.00 & \\
\hline \multicolumn{5}{|l|}{ ER expression } \\
\hline $\operatorname{High}(\geq 50 \%)$ & $125(53 \%)$ & 5.30 & $0.325(0.189-0.559)$ & $<0.001$ \\
\hline Middle (10-50\%) & $57(24 \%)$ & 6.81 & $0.318(0.166-0.610)$ & 0.001 \\
\hline Low $(<10 \%)$ & $28(12 \%)$ & 1.95 & 1.00 & \\
\hline \multicolumn{5}{|l|}{ Adjuvant $\mathrm{CT}$} \\
\hline Anthracycline & $33(14 \%)$ & 2.81 & 1.00 & \\
\hline Taxane & $17(7 \%)$ & 2.53 & $1.016(0.491-2.101)$ & 0.965 \\
\hline Anthracycline+Taxane & $73(31 \%)$ & 4.51 & $0.563(0.321-0.987)$ & 0.045 \\
\hline $\mathrm{CMF}$ & $20(8 \%)$ & 8.20 & $0.355(0.151-0.836)$ & 0.018 \\
\hline None & $76(32 \%)$ & 5.72 & $0.510(0.292-0.894)$ & 0.019 \\
\hline \multicolumn{5}{|l|}{ Adjuvant ET } \\
\hline AI & $109(46 \%)$ & 5.72 & 1.00 & \\
\hline TAM & $91(39 \%)$ & 4.44 & $1.133(0.745-1.721)$ & 0.561 \\
\hline AI/TAM & $16(7 \%)$ & 5.05 & $0.981(0.440-2.188)$ & 0.964 \\
\hline Unknown & $14(6 \%)$ & - & - & \\
\hline \multicolumn{5}{|l|}{ Adjuvant ET duration } \\
\hline$<1$ year & $44(19 \%)$ & 1.86 & 1.00 & \\
\hline $1-3$ years & $90(38 \%)$ & 4.44 & $0.414(0.256-0.669)$ & $<0.001$ \\
\hline $3-5$ years & $61(26 \%)$ & 6.96 & $0.315(0.174-0.572)$ & $<0.001$ \\
\hline$\geq 5$ years & $36(15 \%)$ & 7.80 & $0.248(0.116-0.532)$ & $<0.001$ \\
\hline \multicolumn{5}{|l|}{ TFI } \\
\hline$<1$ year & $162(69 \%)$ & 3.66 & 1.00 & \\
\hline$\geq 1$ year & $55(23 \%)$ & $5.55 ?$ & $0.467(0.264-0.824)$ & 0.009 \\
\hline \multicolumn{5}{|l|}{ DFI } \\
\hline$<2$ years & $53(22 \%)$ & 2.31 & 1.00 & \\
\hline $2-5$ years & $94(40 \%)$ & 4.73 & $0.472(0.297-0.748)$ & 0.001 \\
\hline$\geq 5$ years & $89(38 \%)$ & 5.33 & $0.367(0.221-0.609)$ & $<0.001$ \\
\hline \multicolumn{5}{|l|}{ Age at recurrence } \\
\hline$<50$ years & $47(20 \%)$ & 4.51 & $0.794(0.444-1.422)$ & 0.438 \\
\hline $50-70$ years & $132(56 \%)$ & 4.73 & $0.738(0.461-1.181)$ & 0.205 \\
\hline$\geq 70$ yeras & $57(24 \%)$ & 4.83 & 1.00 & \\
\hline $1 \mathrm{~L}$ treatment & & & & \\
\hline CT & $73(31 \%)$ & 3.66 & $1.273(0.855-1.896)$ & 0.235 \\
\hline ET & $149(63 \%)$ & 5.33 & 1.00 & \\
\hline Unknown & $14(6 \%)$ & - & - & \\
\hline Response to $1 \mathrm{~L}$ treatmen & & & & \\
\hline Good $(\mathrm{CT}+\mathrm{ET})$ & $29+76(45 \%)$ & 7.56 & 1.00 & \\
\hline Poor $(\mathrm{CT}+\mathrm{ET})$ & $42+66(46 \%)$ & 2.44 & $3.511(2.307-5.343)$ & $<0.001$ \\
\hline Unknown & $23(9 \%)$ & - & - & \\
\hline Metastatic site at recurre & & & & \\
\hline Bone only & $79(34 \%)$ & 7.68 & $0.583(0.377-0.905)$ & 0.016 \\
\hline No bone only & $157(66 \%)$ & 3.66 & 1.00 & \\
\hline Lung metastasis & $63(27 \%)$ & 5.72 & $0.900(0.580-1.397)$ & 0.638 \\
\hline No lung metastasis & $173(73 \%)$ & 4.51 & 1.00 & \\
\hline Liver metastasis & $49(21 \%)$ & 1.95 & $2.681(1.776-4.049)$ & $<0.001$ \\
\hline No liver metastasis & $187(79 \%)$ & 5.46 & 1.00 & \\
\hline Visceral metastasis & $115(49 \%)$ & 3.66 & $1.353(0.919-1.996)$ & 0.125 \\
\hline No visceral metastasis & $121(51 \%)$ & 4.73 & 1.00 & \\
\hline Single metastasis & $149(63 \%)$ & 5.55 & 1.00 & \\
\hline Multiple metastases & $87(37 \%)$ & 2.44 & $2.375(1.610-3.509)$ & $<0.001$ \\
\hline
\end{tabular}

ER, Estrogen receptor; CT, chemotherapy; CMF, cyclophosphamide methotrexate fluorouracil; ET, endocrine therapy; AI, aromatase inhibitor; TAM, tamoxifen; TFI, treatment-free interval; DFI, disease-free interval; 1L, first-line. 

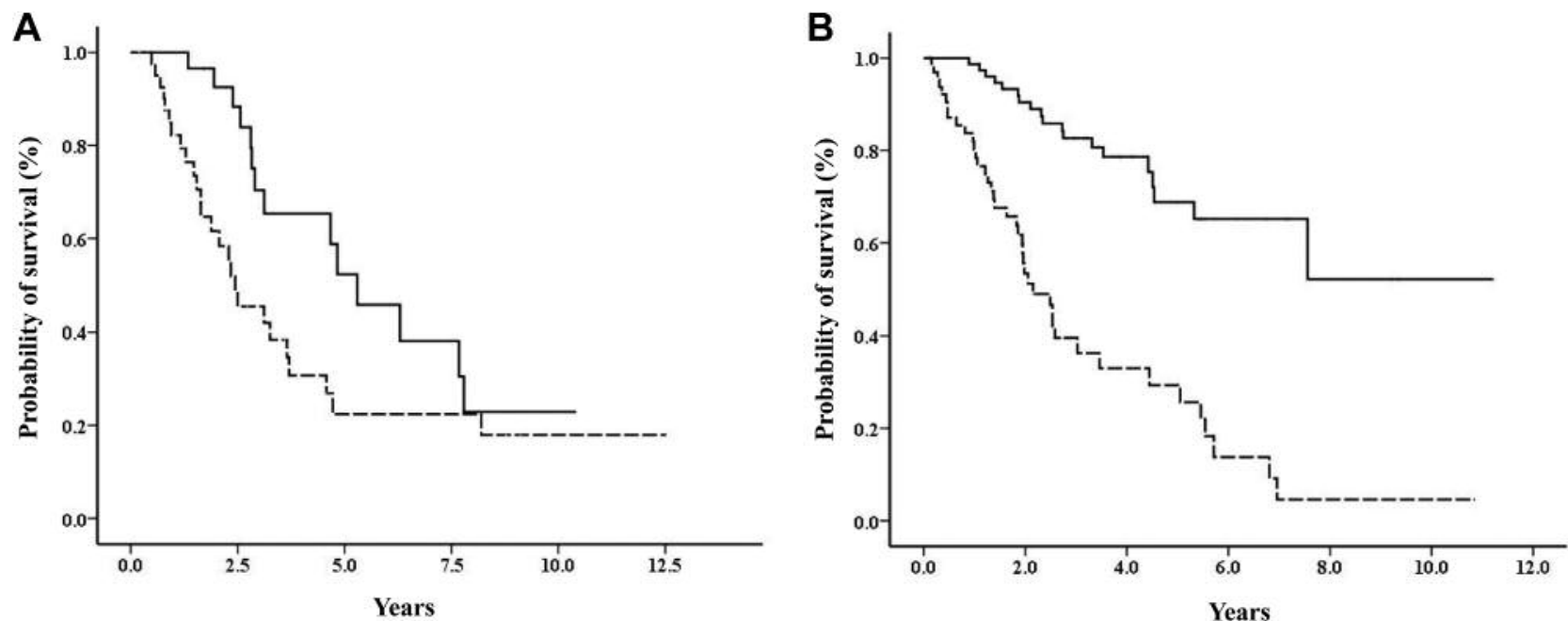

Figure 1. Overall survival according to response to different first-line therapies. Plots show survival of patients treated with (A) first-line chemotherapy (log-rank test, $p<0.028$ ) and $(B)$ first-line endocrine therapy (log-rank test, $p=0.001$ ). Solid lines: patients with good response to first-line therapy; dotted lines: patients with poor response to first-line therapy.

Table II. Multivariate analysis of survival after recurrence.

\begin{tabular}{lcc}
\hline Characteristics & \multicolumn{2}{c}{ Multivariate analysis } \\
\cline { 2 - 3 } & HR $(95 \% \mathrm{CI})$ & $p$-Value \\
\hline Age at diagnosis $\geq 70$ years & $1.406(0.955-2.070)$ & 0.084 \\
Low ER expression & $1.397(0.996-1.957)$ & 0.053 \\
Adjuvant A/T & $0.908(0.681-1.211)$ & 0.512 \\
Adjuvant ET $\geq 5$ years & $0.916(0.554-1.516)$ & 0.733 \\
TFI $<1$ year & $1.576(1.008-2.465)$ & 0.046 \\
DFI<2 years & $1.411(1.057-1.883)$ & 0.019 \\
Response to 1L treatment & $0.586(0.457-0.752)$ & $<0.001$ \\
Bone-only metastasis & $0.743(0.531-1.041)$ & 0.084 \\
Liver metastasis & $1.456(1.110-1.912)$ & 0.007 \\
Multiple metastases & $1.727(1.271-2.347)$ & $<0.001$ \\
\hline
\end{tabular}

ER, Estrogen receptor; A/T, anthracycline or taxane chemotherapy; ET, endocrine therapy; TFI, treatment-free interval; DFI, disease-free interval; $1 \mathrm{~L}$, first-line.

adjuvant treatments, a prolonged DFI implies clinical improvement concerning survival outcomes. Our multivariate analysis indicated that both TFI and DFI should be regarded as important time parameters related to post-recurrence survival. Understanding these time-based variables before recurrence could largely contribute to decisions regarding optimal therapeutic strategies after recurrence.

The metastatic site at first recurrence has been regarded as an important predictive factor for survival after recurrence $(11,18,20,21)$. Our multivariate analysis showed that the

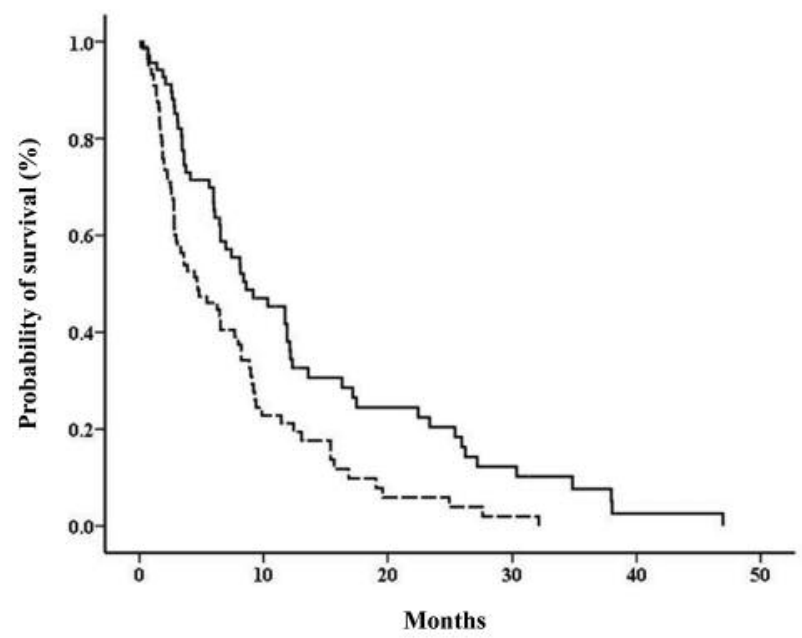

Figure 2. Progression-free survival on second-line treatment for recurrence, according to response to first-line treatment. Solid line: patients with good response to first-line therapy; dotted line: patients with poor response to first-line therapy (log-rank test, $p=0.001$ ).

first metastatic site was independently associated with postrecurrence survival; in particular, both liver and multiple metastases strongly predicted a poor outcome after recurrence. This finding supported the assumption that liver and multiple metastases are indicative of extensive spreading or disseminated cancer cells, which leads to poor survival outcomes $(19,22)$. 
Table III. The relative risk of a poor response to $1 L$-CT, according to patient and tumor characteristics.

\begin{tabular}{|c|c|c|c|}
\hline Characteristics & Number $(\%)$ & OR $(95 \% \mathrm{CI})$ & $p$-Value \\
\hline \multicolumn{4}{|l|}{ Age at diagnosis } \\
\hline$<70$ years & $40(95 \%)$ & 1.00 & \multirow[t]{2}{*}{0.377} \\
\hline$\geq 70$ years & $2(5 \%)$ & $2.309(0.361-14.706)$ & \\
\hline \multicolumn{4}{|l|}{ ER expression } \\
\hline$\geq 10 \%$ & $28(76 \%)$ & 1.00 & \multirow[b]{2}{*}{0.392} \\
\hline$<10 \%$ & $9(24 \%)$ & $1.768(0.480-6.509)$ & \\
\hline \multicolumn{4}{|l|}{ Adjuvant $\mathrm{A} / \mathrm{T}$} \\
\hline Yes & $32(76 \%)$ & 1.00 & \multirow[b]{2}{*}{0.500} \\
\hline No & $10(23 \%)$ & $1.441(0.499-4.149)$ & \\
\hline \multicolumn{4}{|l|}{ Adjuvant ET } \\
\hline$<5$ years & $40(95 \%)$ & $2.309(0.361-14.706)$ & \multirow[t]{2}{*}{0.377} \\
\hline$\geq 5$ years & $2(5 \%)$ & 1.00 & \\
\hline \multicolumn{4}{|l|}{ TFI } \\
\hline$<1$ year & $31(84 \%)$ & $2.323(0.430-12.546)$ & \multirow[t]{2}{*}{0.327} \\
\hline$\geq 1$ year & $6(16 \%)$ & 1.00 & \\
\hline \multicolumn{4}{|l|}{ DFI } \\
\hline$<2$ years & $12(29 \%)$ & $1.528(0.559-4.175)$ & \multirow[t]{2}{*}{0.409} \\
\hline$\geq 2$ years & $30(71 \%)$ & 1.00 & \\
\hline \multicolumn{4}{|c|}{ Bone-only metastasis } \\
\hline Yes & $4(10 \%)$ & 1.00 & \multirow[b]{2}{*}{0.014} \\
\hline No & $38(90 \%)$ & $5.000(1.385-18.182)$ & \\
\hline \multicolumn{4}{|l|}{ Liver metastasis } \\
\hline Yes & $17(40 \%)$ & $1.785(0.643-4.956)$ & \multirow[t]{2}{*}{0.266} \\
\hline No & $25(60 \%)$ & 1.00 & \\
\hline \multicolumn{4}{|c|}{ Multiple metastases } \\
\hline Yes & $18(43 \%)$ & $1.667(0.615-4.513)$ & \multirow[t]{2}{*}{0.315} \\
\hline No & $24(57 \%)$ & 1.00 & \\
\hline
\end{tabular}

1L-CT, First-line chemotherapy; ER, estrogen receptor; A/T, anthracycline or taxane chemotherapy; ET, endocrine therapy; TFI, treatment-free interval; DFI, disease-free interval.

Here, it was found that the response to the first-line recurrence treatment, regardless of whether it was based on CT or on ET, was an independent prognostic factor for postrecurrence survival in HR+/HER2- patients. Furthermore, the PFS response to second-line treatments depended on how good the response to the first-line treatment was, as this correlated with prolonged survival outcomes in general. This finding suggested that the first-line treatment response might be the most important factor in post-recurrence survival for patients with metastatic HR+/HER2- breast cancer. In agreement with this, our study revealed that a poor response to the first-line treatment was significantly related to unfavorable survival after recurrence. Previous studies have also reported several predictors of the response to secondline therapy or specifically to ET for treating recurrence (11, $17,19,21)$. Most patients with a poor response to first-lineET are resistant to it $(15,16)$; therefore, CT should be selected as the second-line treatment. However, little is known about the risk factors associated with the first-line treatment response. Our logistic regression analysis showed
Table IV. The relative risk for poor response to $1 \mathrm{~L}$-ET, according to patient and tumor characteristics.

\begin{tabular}{|c|c|c|c|}
\hline Characteristics & Number (\%) & OR $(95 \% \mathrm{CI})$ & $p$-Value \\
\hline \multicolumn{4}{|l|}{ Age at diagnosis } \\
\hline$<70$ years & $52(79 \%)$ & 1.00 & \\
\hline$\geq 70$ years & $14(21 \%)$ & $2.004(0.805-4.991)$ & 0.135 \\
\hline \multicolumn{4}{|l|}{ ER expression } \\
\hline$\geq 10 \%$ & $51(88 \%)$ & 1.00 & \\
\hline$<10 \%$ & $7(12 \%)$ & $2.162(0.599-7.796)$ & 0.239 \\
\hline \multicolumn{4}{|l|}{ Adjuvant $\mathrm{A} / \mathrm{T}$} \\
\hline Yes & $15(23 \%)$ & 1.00 & \\
\hline No & $51(77 \%)$ & $1.941(0.805-4.678)$ & 0.139 \\
\hline \multicolumn{4}{|l|}{ Adjuvant ET } \\
\hline$<5$ years & $55(83 \%)$ & $1.680(0.684-3.650)$ & 0.285 \\
\hline$\geq 5$ years & $11(17 \%)$ & 1.00 & \\
\hline \multicolumn{4}{|l|}{ TFI } \\
\hline$<1$ year & $51(80 \%)$ & $2.045(0.939-4.444)$ & 0.072 \\
\hline$\geq 1$ year & $13(20 \%)$ & 1.00 & \\
\hline \multicolumn{4}{|l|}{ DFI } \\
\hline$<2$ years & $14(21 \%)$ & $2.004(0.805-5.000)$ & 0.135 \\
\hline$\geq 2$ years & $52(79 \%)$ & 1.00 & \\
\hline \multicolumn{4}{|c|}{ Bone-only metastasis } \\
\hline Yes & $22(33 \%)$ & $0.556(0.281-1.098)$ & 0.091 \\
\hline No & $42(67 \%)$ & 1.00 & \\
\hline \multicolumn{4}{|l|}{ Liver metastasis } \\
\hline Yes & $15(23 \%)$ & $4.176(1.427-12.227)$ & 0.009 \\
\hline No & $51(77 \%)$ & 1.00 & \\
\hline \multicolumn{4}{|c|}{ Multiple metastases } \\
\hline Yes & $28(42 \%)$ & $1.930(0.958-3.889)$ & 0.066 \\
\hline No & $38(58 \%)$ & 1.00 & \\
\hline
\end{tabular}

1L-ET, First-line endocrine therapy; ER, estrogen receptor; A/T, anthracycline or taxane chemotherapy; ET, endocrine therapy; TFI, treatment-free interval; DFI, disease-free interval.

that liver metastasis at recurrence was a significant risk factor for a poor response to first-line-ET, regardless of whether patients were resistant to this type of therapy. This finding suggested that patients with liver metastasis should be treated with first-line CT to improve the subsequent prognosis. Recently, new molecular targeted drugs, such as inhibitors of mTOR, CDK4/6, and PIK3CA, have become clinically available for treatments in combination with ET for HR+/HER2- metastatic cancer patients $(12,23)$. The continuous development of novel cancer treatments and molecular targeted therapies may improve the survival of these patients (24-28). In particular, for those at high risk, optimal treatments for recurrence, in addition to novel targeted agents, could reduce the cancer's resistance to the subsequent treatments and lead to a better prognosis.

The present study had certain limitations. First, as a retrospective chart review without validation, it was not possible to avoid a selection bias. However, the selection of patients with $\mathrm{HR}+/ \mathrm{HER} 2-$ recurrent breast cancer, and the exclusion of HER2+, triple negative, or de novo breast 
cancer patients, allowed the study of post-recurrence survival in HR+/HER2- metastatic breast cancer patients despite the small sample size. Moreover, here we presented realistic data, based on actual clinical practice. Future studies with a larger cohort of patients might provide more conclusive evidence of prognostic value for the factors we identified.

In conclusion, this retrospective study using real-world medical records identified clinical prognostic factors that predicted the post-recurrence survival in HR+/HER2+ metastatic breast cancer. We found that the response to a first-line treatment for recurrence could be the most important factor for post-recurrence survival. Moreover, liver metastasis at recurrence was identified as both a strong risk factor for a poor response to first-line treatment for recurrence as well as a significant prognostic factor for unfavorable survival after recurrence. Our study provided frontline physicians with important clinical clues to achieving optimal treatment strategies and for accurately assessing patients with HR+/HER2- metastases.

\section{References}

1 National Cancer Institute. Surveillance, Epidemiology, and End Results Program. SEER Stat Fact Sheets: Breast Cancer. 2017. http://seer.cancer.gov/statfacts/html/breast.html (accessed October 5, 2018).

2 Hortobagyi GN, de la Garza Salazar J, Pritchard K, Amadori D, Haidinger R, Hudis CA, Khaled H, Liu MC, Martin M, Namer M, O'Shaughnessy JA, Shen ZZ and Albain KS: ABREAST Investigators: The global breast cancer burden: variations in epidemiology and survival. Clin Breast Cancer 6: 391-401, 2005.

3 EBCTCG (Early Breast Cancer Trialists' Collaborative Group), McGale P, Taylor C, Correa C, Cutter D, Duane F, Ewertz M, Gray R, Mannu G, Peto R, Whelan T, Wang Y, Wang Z and Darby $S$ : Effect of radiotherapy after mastectomy and axillary surgery on 10-year recurrence and 20-year breast cancer mortality: meta-analysis of individual patient data for 8135 women in 22 randomised trials. Lancet 383: 2127-2135, 2014.

4 Early Breast Cancer Trialists' Collaborative Group (EBCTCG), Peto R, Davies C, Godwin J, Gray R, Pan HC, Clarke M, Cutter D, Darby S, McGale P, Taylor C, Wang YC, Bergh J, Di Leo A, Albain K, Swain S, Piccart M and Pritchard K: Comparisons between different polychemotherapy regimens for early breast cancer: meta-analyses of long-term outcome among 100,000 women in 123 randomised trials. Lancet 379: 432-444, 2012.

5 Early Breast Cancer Trialists' Collaborative Group (EBCTCG), Darby S, McGale P, Correa C, Taylor C, Arriagada R, Clarke M, Cutter D, Davies C, Ewertz M, Godwin J, Gray R, Pierce L, Whelan T, Wang Y and Peto R: Effect of radiotherapy after breast-conserving surgery on 10-year recurrence and 15-year breast cancer death: meta-analysis of individual patient data for 10,801 women in 17 randomised trials. Lancet 378 : 1707-1716, 2011.

6 Haffty BG, Fischer D, Beinfield M and McKhann C: Prognosis following local recurrence in the conservatively treated breast cancer patient. Int J Radiat Oncol Biol Phys 21: 293-298, 1991.
7 Giuliani J and Bonetti A: Trends in survival for patients with metastatic breast cancer: is survival improving? Tumori 101: 347-352, 2015.

8 Chung CT and Carlson RW: Goals and objectives in the management of metastatic breast cancer. Oncologist 8: 514-520, 2003.

9 Hortobagyi GN: Treatment of breast cancer. N Engl J Med 339: 974-984, 1998.

10 Başaran GA, Twelves C, Diéras V, Cortés J and Awada A: Ongoing unmet needs in treating estrogen receptorpositive/HER2-negative metastatic breast cancer. Cancer Treat Rev 63: 144-155, 2018.

11 Ogiya A, Yamazaki K, Horii R, Shien T, Horimoto Y, Masuda N, Inao T, Hosoda M, Ishida N, Osako T, Takahashi M, Endo Y, Miyoshi $\mathrm{Y}$, Yasojima $\mathrm{H}$, Tomioka $\mathrm{N}$ and Yamashita $\mathrm{H}$ : Collaborative Study Group of Scientific Research of the Japanese Breast Cancer Society. Post-relapse survival in patients with the early and late distant recurrence in estrogen receptorpositive HER2-negative breast cancer. Breast Cancer 24: 473482, 2017.

12 Perez EA: Treatment strategies for advanced hormone receptorpositive and human epidermal growth factor 2-negative breast cancer: the role of treatment order. Drug Resist Updat 24: 13$22,2016$.

13 National Comprehensive Cancer Network: NCCN clinical practice guidelines in oncology (NCCN Guidelines) - Breast cancer version 2. 2018. https://www.nccn.org/professionals/ physician_gls/pdf/breast.pdf (accessed October 5, 2018).

14 Cardoso F, Costa A, Senkus E, Aapro M, André F, Barrios CH, Bergh J, Bhattacharyya G, Biganzoli L, Cardoso MJ, Carey L, Corneliussen-James D, Curigliano G, Dieras V, El Saghir N, Eniu A, Fallowfield L, Fenech D, Francis P, Gelmon K, Gennari A, Harbeck N, Hudis C, Kaufman B, Krop I, Mayer M, Meijer H, Mertz S, Ohno S, Pagani O, Papadopoulos E31, Peccatori F, Penault-Llorca F, Piccart MJ, Pierga JY, Rugo H, Shockney L, Sledge G, Swain S, Thomssen C, Tutt A, Vorobiof D, Xu B, Norton L and Winer E: 3rd ESO-ESMO international consensus guidelines for Advanced Breast Cancer (ABC 3). Breast 31: 244259, 2017.

15 Zhang XH, Giuliano M, Trivedi MV, Schiff R and Osborne CK: Metastasis dormancy in estrogen receptor-positive breast cancer. Clin Cancer Res 19: 6389-6397, 2013.

16 Ignatiadis $M$ and Sotiriou C: Luminal breast cancer: from biology to treatment. Nat Rev Clin Oncol 10: 494-506, 2013.

17 Lee SB, Sohn G, Kim J, Chung IY, Lee JW, Kim HJ, Ko BS, Son BH and Ahn SH: Survival analysis according to period and analysis of the factors influencing changes in survival in patients with recurrent breast cancer: a large-scale, single-center study. Breast Cancer 25: 639-649, 2018.

18 Chang J, Clark GM, Allred DC, Mohsin S, Chamness G and Elledge RM: Survival of patients with metastatic breast carcinoma: importance of prognostic markers of the primary tumor. Cancer 97: 545-553, 2003.

19 Tsuji W, Teramukai S, Ueno $\mathrm{M}$, Toi $\mathrm{M}$ and Inamoto $\mathrm{T}$ : Prognostic factors for survival after first recurrence in breast cancer: a retrospective analysis of 252 recurrent cases at a single institution. Breast Cancer 21: 86-95, 2014.

20 Giordano SH, Buzdar AU, Smith TL, Kau SW, Yang Y and Hortobagyi GN: Is breast cancer survival improving? Cancer 100: 44-52, 2004. 
21 Carbognin L, Sperduti I, Ciccarese M, Fabi A, Petrucelli L, Vari S, Forcignanò RC, Nortilli R, Vicentini C, Pilotto S, Merler S, Zampiva I, Brunelli M, Manfrin E, Giannarelli D, Tortora G and Bria E: Prognostic model for advanced breast carcinoma with luminal subtype and impact of hormonal maintenance: Implications for post-progression and conditional survival. Breast 29: 24-30, 2016.

22 Wyld L, Gutteridge E, Pinder SE, James JJ, Chan SY, Cheung KL, Robertson JF and Evans AJ: Prognostic factors for patients with hepatic metastases from breast cancer. Br J Cancer 89: 284290, 2003.

23 Johnston SR: Enhancing endocrine therapy for hormone receptor-positive advanced breast cancer: Cotargeting signaling pathways. J Natl Cancer Inst 107: 10, 2015.

24 Baselga J, Campone M, Piccart M, Burris HA 3rd, Rugo HS, Sahmoud T, Noguchi S, Gnant M, Pritchard KI, Lebrun F, Beck JT, Ito Y, Yardley D, Deleu I, Perez A, Bachelot T, Vittori L, Xu Z, Mukhopadhyay P, Lebwohl D and Hortobagyi GN: Everolimus in postmenopausal hormone-receptor-positive advanced breast cancer. N Engl J Med 366: 520-529, 2012.

25 Cristofanilli M, Turner NC, Bondarenko I, Ro J, Im SA, Masuda N, Colleoni M, DeMichele A, Loi S, Verma S, Iwata H, Harbeck N, Zhang K, Theall KP, Jiang Y, Bartlett CH, Koehler M and Slamon D: Fulvestrant plus palbociclib versus fulvestrant plus placebo for treatment of hormone-receptor-positive, HER2negative metastatic breast cancer that progressed on previous endocrine therapy (PALOMA-3): final analysis of the multicentre, double-blind, phase 3 randomised controlled trial. Lancet Oncol 17: 425-439, 2016.
26 Finn RS, Martin M, Rugo HS, Jones S, Im SA, Gelmon K, Harbeck N, Lipatov ON, Walshe JM, Moulder S, Gauthier E, Lu DR, Randolph S, Diéras V and, Slamon DJ: Palbociclib and Letrozole in advanced breast cancer. N Engl J Med 375: 19251936, 2016.

27 Goetz MP, Toi M, Campone M, Sohn J, Paluch-Shimon S, Huober J, Park IH, Trédan O, Chen SC, Manso L, Freedman OC, Garnica Jaliffe G, Forrester T, Frenzel M, Barriga S, Smith IC, Bourayou N and Di Leo A: MONARCH 3: Abemaciclib as initial therapy for advanced breast cancer. J Clin Oncol 35: 3638-3646, 2017.

28 Sledge GW Jr., Toi M, Neven P, Sohn J, Inoue K, Pivot X, Burdaeva O, Okera M, Masuda N, Kaufman PA, Koh H, Grischke EM, Frenzel M, Lin Y, Barriga S, Smith IC, Bourayou $\mathrm{N}$ and Llombart-Cussac A: MONARCH 2: Abemaciclib in combination with fulvestrant in women with HR+/HER2advanced breast cancer who had progressed while receiving endocrine therapy. J Clin Oncol 35: 2875-2884, 2017.

Received October 15, 2018

Revised November 14, 2018

Accepted November 15, 2018 